\title{
JAWABAN SOAL UTS 2018/2019 MATAKULIAH HAKI
}

\section{AGUS WAHYUDI}

185100037P

Fakultas Komputer, GAGAL 000

Aguswahyudi.student@umitra.ac.id

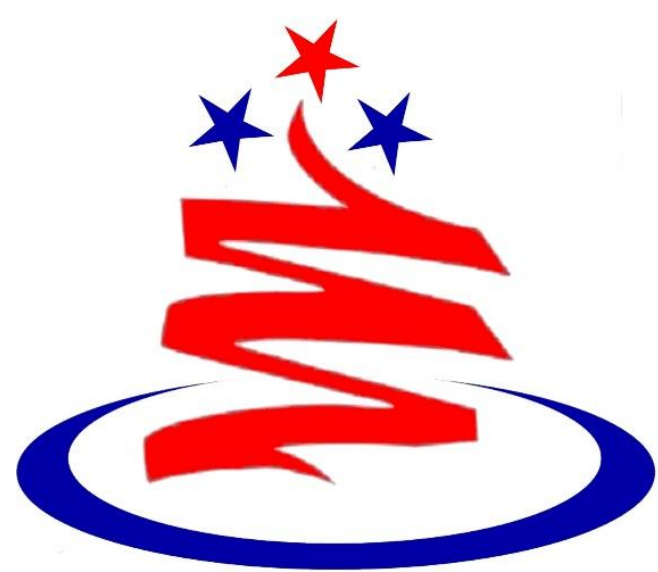

UnIVERSITAS mITRA InDONESIA 


\section{A. STUDI KASUS ( SK )}

Pertanyaan Type A :

Paparkan dan jelaskan produck knowlwdge (KS) / produk tim anda (KP) Jawaban : Produck Reog Super Computer yang dirancang oleh tiga pemuda asal Indonesia tepatnya di pulau Sumatra kota Bandar Lampung, memiliki desain yang terlihat sangat kokoh dengan menggunakan chassis alumunium. Lapisan matte yang melindungi chassis nya membuat terbebas dari sidik jari yang mungkin menempel saat pengguna memakainya, super computer yang akan mengubah teknologi khususnya di Indonesia yang memiliki spesipikasi yang sangat baik dari yang terbaik, berikut penjelasa spesifikasi dari super computer Reog:

$\checkmark$ Prosesor : intel core i7 3770K

$\checkmark$ Motherboard : ASUS Sabertooth Z77

$\checkmark$ VGA : Gigabyte GTX690

$\checkmark$ RAM : DDR3 Intel Extreme 32GB

$\checkmark$ Hardisk : western digital 1TB Cariviar Black

$\checkmark$ SSD : OCZ Vector $256 \mathrm{~Gb}$

$\checkmark$ DVD room : Samsung Bluray Combo SE-406B

$\checkmark$ Chassis : alumunium matte

$\checkmark$ Cooler / kipas : Corsair H100i

$\checkmark$ PSU : SeaSonic P860

Dapat kita lihat mulai dari prosesor nya yang menggunakan core i7 yang notebene nya merupakan High prosesor, VGA nya berkelas, RAM nya 32 GB, dan Hardisk nya 1TB dapat leluasa menyimpan lembar pekerjaan pengguna atau softwaresoftware si pengguna butuhkan pada kehidupan teknologinya. Produck Super Computer yang membuat nya beda dari merk lain adalah dari lapisan chassis atau casing nya yang terbuat dari alumunium yang dilapisi matte yang terhindar dari sidik jari pengguna saat Super Computer Reog di oprasikan. 


\section{B. STUDI REFERENSI ( SP )}

Pertanyaan Jenis A :

Jelaskan Produck-produck dalam Hak Atas Kekayaan Intelektual Jawaban :

Produk-produk HaKI (Hak atas Kekayaan Intelektual) perangkat lunak, untuk 1. Perangkat Lunak Berpemilik

- Sistem Operasi Mac.Os milik Apple.inc

- Aplikasi AutoCAD milik Autodesk

2. Perangkat Komersial

- Sistem Operasi MS.Windows milik Microsoft Coorporation

- Aplikasi MS.Office

3. Perangkat Lunak Semi Bebas

- Program PGP

- Aplikasi Smadav

4. Perangkat Lunak Publik Domain

- Sistem Operasi Windows 98

- Aplikasi STP Mp3 Player

5. Perangkat Lunak Freeware

- Program Java Runtime Environment

- Aplikasi Paint.net. Rocket Dock, Ccleaner.

6. Perangkat Lunak Shareware

- Sistem Operasi beta version, seperti Windows Xp beta/trial

- Aplikasi StyleXp, Window Blind, WinRAR

7. Perangkat Lunak Bebas

- Sistem Operasi BSD

- Aplikasi Mozilla

8. Perangkat Lunak Copyleft / Non Copyleft

Copyleft

- Sistem Operasi Debian, Backtrack

- Aplikasi OpenOffice 


\section{Non Copyleft}

- Sistem Operasi X Window Sistem

9. Perangkat Lunak Kode Terbuka (Open Source)

- Sistem Operasi Linux, Ubuntu, CentOs, Fedora

- Aplikasi Mozilla

10. Perangkat Lunak GPL/GNU

- Sistem Operasi Free BSD

- Aplikasi X Perl

\section{STUDI PENALARAN ( SP )}

Pertanyaan Kategori 1 :

Buatlah penjelasan secara detail produck Samsung dan beberapa bagian

Hak yang ikut serta didalamnya

Jawaban :

\section{SAMSUNG GALAXY S9+}

Samsung Galaxy S9+ (Samsung Galaxy S9 Plus). Bahkan, HP ini lebih unggul dibanding saudaranya Samsung Galaxy S9. Banyaknya kelebihan yang dimiliki HP ini membuat HP tergolong menarik untuk dipinang.

Samsung Galaxy S9+ harus diakui memang punya banyak keunggulan dibanding kelemahan. Carisinyal mencatat ada 10 kelebihan dari Samsung Galaxy S9+ ini.

\section{SPESIFIKASI SAMSUNG GALAXY S9+}

1. Rilis: Februari 2018

2. Layar: Super AMOLED 6.2 inches, Corning Gorilla Glass 5

3. Resolusi Layar: 1440 x 2960 pixels, 18.5:9 ratio

4. Chipset: Exynos 9810 Octa - EMEA or Qualcomm MSM8998 Snapdragon 845 - USA \& China

5. CPU: Octa-core $(4 \times 2.8 \mathrm{GHz}$ Mongoose M3 \& 4×1.7 GHz Cortex-A55) EMEA version or Octa-core $(4 \times 2.7 \mathrm{GHz}$ Kryo 385 Gold \& $4 \times 1.7 \mathrm{GHz}$ Kryo 385 Silver) - USA \& China version 
6. GPU: Mali-G72 MP18 - EMEA or Adreno 630 - US model

7. Memori Internal: 64/128/256 GB, 6 GB RAM

8. Memori Eksternal: microSD, up to 400 GB (uses SIM 2 slot) - dual SIM model only

9. Kamera Belakang: Dual: 12 MP (f/1.5-2.4, 26mm, 1/2.55", $1.4 \mu \mathrm{m}$, Dual Pixel PDAF) + 12MP (f/2.4, 52mm, 1/3.6", $1 \mu \mathrm{m}$, AF), OIS, phase detection autofocus, $2 \mathrm{x}$ optical zoom, LED flash, simultaneous $4 \mathrm{~K}$ video

10. Kamera Depan: 8 MP (f/1.7, 25mm, 1/3.6", $1.22 \mu \mathrm{m})$, autofocus, 1440p@30fps, dual video call, Auto HDR

11. Baterai: Non-removable Li-Ion 3500 mAh

\section{KELEBIHAN SAMSUNG GALAXY S9+}

\section{Tampilan Fisual Terbaik}

Dengan dimensi layar 6.2 inch, Samsung Galaxy S9+ memberikan tampilan visual yang lebih lebar. Layarnya mengusung Quad HD+ 1440 x 2960 pixels dengan kerapatan layar 521ppi. Dengan rasio layar 18.5:9, Samsung Galaxy S9+ memberikan pengalaman menampilkan video yang cerah dan memanjakan mata. Bukan tedeng aling-aling menyebut layar Galaxy S9+ sebagai yang terbaik. Bersama dengan Samsung Galaxy S9, Samsung Galaxy S9+ dinobatkan sebagai HP dengan layar smartphone terbaik oleh DisplayMate.

embedanya, Samsung Galaxy S9 hanya menampilkan dimensi layar 5.8 inch. Sementara Samsung Galaxy S9+ memberikan tampilan lebih lebar. Tentu saja untuk menikmati konten HDR lewat Super AMOLED Quad HD lebih menarik dan lebih luas dibanding layar Samsung Galaxy S9. Tak berlebihan jika menyebut tampilan visual Samsung Galaxy S9+ adalah yang terbaik jika harus diadu dengan "saudara sendiri" Samsung Galaxy S9. Soal layar pada HP ini, jelas tak perlu diragukan lagi kualitasnya. Trsutedreviews juga mengamini kalau tampilan layar Super 
AMOLED pada HP ini adalah yang terbaik dan bisa membebaskan penggunanya mengatur mode tampilan.

\section{Desain Anti Debu dan Anti Air Yang Nyaman Digenggam}

Dengan layar yang lebih panjang, Samsung Galaxy S9+ memang tampak bongsor. HP ini punya dimensi $158.1 \times 73.8$ x $8.5 \mathrm{~mm}$ dengan berat 189 gram. Terlihat lebar dan agak berat memang, tapi feel menggenggam HP ini tergolong baik dan nyaman digenggam. Desain bodi HP ini terbilang mewah, apalagi HP ini punya panel kaca melengkung di bagian depan dan belakang. Panel tersebut dipisahkan oleh bingkai aluminium yang memberi sentuhan desain mewah. Tak hanya punya desain mewah, HP ini juga sudah punya sertifikasi IP68. Dengan mengantongi serifikasi tersebut, artinya Galaxy S9 Plus mampu bertahan di dalam air pada kedalaman 1,5 meter selama 30 menit. Dengan sertifikasi tersebut, HP ini juga sudah tahan debu.

\section{Posisi Fingerprint yang Lebih Baik}

Samsung Galaxy S9+ memperbaiki hal kecil yang berpengaruh pada user experience, posisi sensor sidik jari. Pada seri Samsung Galaxy S8, posisi sensor sidik berada di samping kamera belakang yang membuatnya kurang nyaman diakses. Hal yang sama terjadi pada seri Samsung Galaxy Note 8. Pada seri Samsung Galaxy S9 dan Samsung Galaxy S9+, posisi sensor sidik jari berada di tempat yang tepat. Posisinya sejajar vertikal bersama kamera. Hanya saja khusus di Galaxy S9+, tempat sensor sidik jarinya lebih luas sehingga lebih nyaman untuk telapak jari. Satu nilai lebih yang patut diapresiasi tentunya.

\section{Kualitas Audio Dolby Atmos + AKG}

Kualitas audio Samsung Galaxy S9+ juga patut diapresiasi. GSMArena 
mengatakan kalau kualitas suara yang dihasilkan oleh HP ini terbaik. Bahkan, lebih baik jika dibandingkan HP flagship lainnya semacam iPhone X maupun Google Pixel 2. Menurut GSMArena, kualitas suara HP terdengar lantang.

Wajar saja kualitas suara HP ini terdengar baik. Pasalnya, HP ini punya dual speaker kanan dan kiri dengan kualitas teknologi Dolby Atmos dan tuned by AKG. Selain tampilan layar yang sempurna, kualitas audio yang terdengar baik ini juga jadi faktor lain yang membuat Samsung Galaxy S9+ menarik untuk dilirik.

\section{Performa Yang Tak Tertandingkan}

Samsung Galaxy S9+ yang beredar resmi di Indonesia adalah varian yang dibekali dengan Exynos 9810. Varian lain menggunakan chipset Snapdragon 845 yang khusus untuk pasar Amerika dan Cina. Karena hal ini, mari fokus mencari tahu performa Samsung Galaxy S9+ yang dibekali Exynos 9810.

Sebagai informasi, chipset Exynos 9810 adalah chipset besutan Samsung yang dibuat dengan 10nm FinFET. Terdapat prosesor octa core Mongoose generasi ketiga dan GPU 18 core Mali G72 pada chipset ini. Dengan spesifikasi tersebut, HP ini mampu memberikan performa kencang. Terlihat dari hasil bencrmark dari GSMArena berikut ini.

\section{Dual Kamera Belakang Dual Aperture}

Samsung Galaxy S9+ hadir dengan kamera depan 8 MP yang punya bukaan f/1.7 dan fitur Auto HDR. Kameranya bisa digunakan untuk selfie. Berdasarkan pengujian dari Techradar, hasil kamera selfie HP ini tidak berbeda jauh dengan kamera depan Samsung Galaxy S8+. Daya tarik HP ini adalah kamera belakang. Kamera belakang HP ini hadir dengan dual kamera. Kamera pertama mengusung 12 MP dengan dual aperture. Aperture pertama punya angka f/1.5 untuk foto dengan cahaya 
rendah. Yang kedua adalah aperture f/2.4 untuk cahaya terang. Kamera kedua pada bagian belakang juga mengusung 12 MP dengan bukaan f/2.4. Dengan kombinasi dual kamera dan dual kamera jelas membuat kamera belakang Samsung Galaxy S9+ punya nilai lebih. Apalagi kameranya juga punya fitur Live Focus seperti contoh pada foto berikut ini.

\section{Super Slow-motion $960 \mathrm{fps}$}

Serupa dengan Samsung Galaxy S9, Samsung Galaxy S9+ juga punya fitur slow-motion. Dengan fitur ini, Anda bisa memperlambat rekaman video 960fps. Caranya adalah dengan melambatkan video dengan durasi 0,2 detik kemudian menjadi 6 detik. Jadi, Anda bisa melihat gerakan air yang pelan seperti pada video di atas. Fitur slow-motion akan sangat berguna untuk seru-seruan. Anda yang suka berkreasi dengan video, akan menyukai fitur ini. Jelas Anda juga bisa pamer video slow-motion memakai HP ini di media sosial.

\section{Intelligent Scan}

Intellegent Scan adalah fitur dari Samsung yang sebenarnya tergolong baik jadi kelebihan tersendiri. Dengan fitur ini, Anda bisa membuka OS Samsung dengan cara memindai bola mata (iris scan) dan memindai wajah (face recognition). Bisa dibilang, fitur ini adalah fitur yang menggabungkan Iris Scan dan Face Recognition. Meski Apple punya sistem keamanan yang lebih baik, tapi di Android sistem ini bisa dibilang salah satu yang cukup baik.

\section{Bixby yang Lebih Pintar}

Bixby merupakan asisten pintar yang dibuat khusus oleh Samsung. Fitur 
ini hadir sebagai lawan dari Apple Siri. Bixby pada Galaxy S9 dan Galaxy S9+ bekerja lebih pintar dibanding di seri sebelumnya. Hal ini berkat adanya Bixby Vision dan Bixby Voice. Kehadiran Bixby Vision dan Bixby Voice pada Galaxy S9+ membuat asisten pintar ini lebih pintar. Cara memanfaatkan Bixby Vision adalah dengan memotret tulisan bahasa asing untuk kemudian diterjemahkan oleh Bixby seperti contoh pada foto di atas. Sementara cara memanfaatkan Bixby Voice, misalnya dengan menyuruh Bixby untuk melakukan tweet di Twitter dengan hanya mengandalkan suara. Fitur

\section{Baterai yang Tergolong Baik}

Baterai pada Samsung Galaxy S9+ memiliki kapasitas 3.500 mAh. Kapasitas baterai HP ini sendiri sama dengan seri Galaxy S8+ yang berarti tidak ada peningkatan. Samsung tampaknya belajar dari kasus meledaknya Galaxy Note 6. Mulai dari kasus itu, Samsung seolah tak berani memberi kapasitas baterai yang besar. Meskipun kapasitas baterainya standar, berdasarkan data perbandingan yang dimuat di PhoneArena, kemampuan daya tahan baterai ternyata mengalami peningkatan. Baik Galaxy S9 dan Galaxy S9+ punya daya tahan baterai yang yang mengalami peningkatan dibanding Galaxy S8 dan Galaxy S9, meski memang tidak signifikan. Oh yah, soal fast charging, Samsung Galaxy S9+ jelas mendukung teknologi fast charging atau pengisian daya cepat. Hasl pengisian daya cepatnya memang tidak secepat di kelas flagship tapi masih terbilang mumpuni. Hal ini didasari dari hasil yang didapatkan oleh GSMArena yang dalam 30 menit pengisian daya, baterai terisi $37 \%$ saja. Techradar juga mendapatkan persentasi yang hampir mirip. Dalam pengisian daya 30 menit, Samsung Galaxy S9+ yang diuji Techradar mampu mendapatkan daya sebesar 38\%. Untuk sampai penuh, waktu yang dibutuhkan ternyata mencapai 1 jam 41 menit. Menilik hasilnya, bisa dikatakan cukup baik. 


\section{KEKURANGAN SAMSUNG GALAXY S9+}

\section{Tak Berbeda Jauh dengan Galaxy S8+}

Harus diakui kalau bentuk desain Samsung Galaxy S9+ ini banyak dibilang tidak terlalu jauh desainnya dengan Samsung Galaxy S8+. Perbedaannya tidak terlalu mencolok sehingga kadang orang yang punya Galaxy S8+ tidak terlalu tergoda untuk mengganti dengan Galaxy S9+. Meski harus diakui, ada banyak fitur dan kemampuan yang lebih baik di Galaxy S9+ dibandingkan Galaxy S8+. Tapi, fitur tersebut bukan yang terlalu signifikan. Mungkin juga karena pengguna Galaxy S8+ tidak terlalu butuh kinerja yang terlalu cepat atau fitur lain yang ada di Galaxy S9+ tapi tak ada di Galaxy S8+ tidak terlalu dibutuhkan. Berdasarkan hal tersebut, jelas tak ada yang jauh beda dari Samsung Galaxy S8+ dan Samsung Galaxy S9+ dari sisi desain. Perbedaan paling mencolok hanya dari fitur maupun hardware yang itupun belum tentu dibutuhkan.

\section{Fitur yang Tak Terlalu Inovatif}

Samsung Galaxy S9+ harus diakui punya daya pikat pada kamera belakang dan kecepatan prosesornya. Fitur Bixby Vision juga jadi daya tarik lain. Tapi selebihnya, hampir tak ada fitur yang inovatif. Fitur-fitur yang ada terasa seperti gimmick saja yang membuat Samsung seolah melakukan hal yang juga bisa dilakukan Apple. Tengok saja fitur AR Emoji yang merupakan tandingan untuk Animoji miliki Apple di perangkat iPhone. Fitur Intellegent Scan juga merupakan fitur yang mencoba menandingi Face ID milik Apple. Bahkan, Bixby juga seolah ingin lebih pintar dan beda dibanding Apple Siri. Fitur-fitur yang tadi disebutkan memang menarik tapi sayang fitur-fitur tersebut kurang inovatif. Satu fitur yang inovatif dan patut diapresiasi adalah dual aperture pada HP ini. 


\section{Sangat Mahal}

Sudah bukan rahasia kalau seri Plus pada seri Galaxy dibanderol dengan harga lebih mahal, begitu juga dengan Samsung Galaxy S9+. Harga HP ini lebih mahal dibanding seri HP flagship kebanyakan. Bahkan, dibanding Samsung Galaxy S9 juga harganya lebih mahal. Harga termahal Samsung Galaxy S9+ mendekati harga satu buah motor. Jadi, jika Anda butuh HP ini, barangkali Anda yang punya dananya terbatas barangkali perlu mencicil untuk bisa dapat HP ini. Tapi jelas mencicil bukan solusi yang baik untuk mendapatkan barang. Sudah jelas, harga terlalu mahal adalah kelemahan dari HP Samsung kelas flagship, termasuk Samsung Galaxy S9+

\section{KESIMPULAN}

Simpulan Samsung Galaxy S9+ adalah HP dengan kinerja kencang yang akan membuat semua orang tak perlu ragu kemampunya, baik untuk main game maupun untuk menjalankan aplikasi berat. HP ini juga punya keunggulan di sisi kamera yang tergolong revolusioner dengan dual kamera dan dual aperture. Tentu fitur-fitur lain yang jadi daya tarik HP ini juga tergolong baik dan jadi nilai lebih, apalagi fitur video slowmotion. Tapi, fitur-fitur tadi tidak bisa didapatkan dengan harga murah. HP ini adalah HP mahal yang harga termahalnya bisa menghabiskan gaji 4 bulan pegawai dengan UMR di Jakarta. Tertarik? 


\section{REFERENSI}

[1] A. S. Putra And O. M. Febriani, "Knowledge Management Online Application In Pdam Lampung Province," In Prosiding International Conference On Information Technology And Business (Icitb), 2018, Pp. 181-187.

[2] A. S. Putra, O. M. Febriani, And B. Bachry, "Implementasi Genetic Fuzzy System Untuk Mengidentifikasi Hasil Curian Kendaraan Bermotor Di Polda Lampung," J. Sist. Inf. Dan Manaj. Basis Data, Vol. 1, No. 1, Pp. 21-30, 2018.

[3] O. M. Febriani And A. S. Putra, "Sistem Informasi Monitoring Inventori Barang Pada Balai Riset Standardisasi Industri Bandar Lampung," J. Inform., Vol. 13, No. 1, Pp. 90-98, 2014.

[4] Putra, Arie Setya. "2018 Artikel Struktur Data, Audit Dan Jaringan Komputer." (2018).

[5] Putra, A. S. (2018, July 17). Paperplain Fundamental Create Application With Borland Delphi 7.0 University Of Mitra Indonesia. Retrieved From Osf.Io/Pbrn9. 